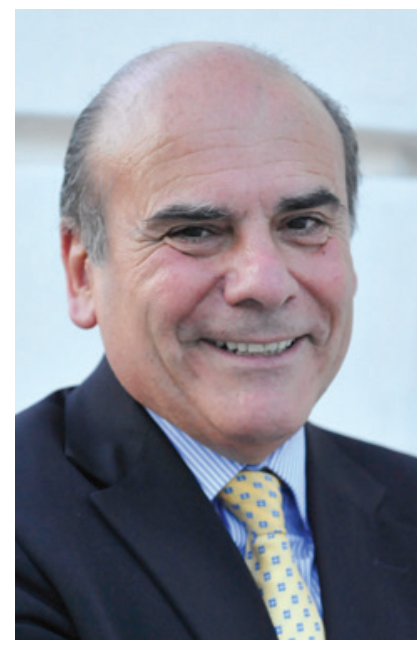

\title{
Os 17 Objetivos de Desenvolvimento Sustentável e a Presbiopia: Relações Entre Qualidade de Vida, Saúde e Produtividade
}

\section{The 17 Sustainable Development Goals and Presbyopia: Relationships Between Quality of Life, Health and Productivity}

António Rendas

O número de setembro deste ano da revista Lancet Global Health publica um artigo original ${ }^{1}$ baseado num ensaio randomizado, realizado na Índia, que mostra o efeito favorável da correção da presbiopia na produtividade de trabalhadores das plantações de chá. Os autores efetuaram detalhadas revisões da literatura, a partir de julho de 1975 e até novembro de 2017, não tendo encontrado qualquer estudo randomizado desta natureza em países de baixo e médio rendimento (low-income and medium-income countries).

Numa altura em que o mundo se encontra a tentar reequacionar o conceito e as consequências da globalização e em que enfrenta problemas complexos de desenvolvimento sustentável, vale a pena assinalar estes projetos científicos, ligados à saúde, que utilizam metodologias internacionalmente aceites para provar, de uma forma clara, aquilo que muitos profissionais da saúde sabem ser incontestável nos respetivos espaços de intervenção.

As mesmas convicções têm sido assumidas relativamente aos 17 Objetivos de Desenvolvimento Sustentável que as Nações Unidas promovem desde 2016. Todos concordamos que, até 2030, é essencial: erradicar a pobreza, erradicar a fome, garantir uma saúde e uma educação de qualidade, alcançar a igualdade de género, garantir água potável e saneamento, garantir fontes de energia renováveis e fiáveis, promover o trabalho digno e o crescimento económico, promover a industrialização inclusiva e fomentar a inovação, reduzir as desigualdades, garantir padrões de consumo e de produção sustentáveis, adotar medidas urgentes para combater as alterações climáticas, proteger a vida marinha e a vida terrestre, promover a paz, a justiça e construir instituições eficazes, reforçar parcerias para o desenvolvimento sustentável.
No entanto, a questão de fundo é saber como vão ser postas em prática estas iniciativas e por quem.

○ estudo acima mencionado aborda um problema de saúde, agravado com o envelhecimento, que é global e que afeta a qualidade de vida de uma percentagem crescente de habitantes de qualquer continente do nosso planeta. A relação com a produtividade, avaliada neste caso num contexto agrícola, pode ser extrapolada para outras sociedades mais "avançadas" até à "aldeia digital". Medir o impacto destas intervenções, que melhoram a qualidade de vida, junto de cada indivíduo e em grupos profissionais bem caraterizados, será essencial para provar como se podem cumprir, com rigor, as metas definidas nos 17 Objetivos de Desenvolvimento Global. Neste caso são visados os objetivos 1 (pobreza), 3 (saúde), 5 (igualdade de género) e 8 (trabalho digno e crescimento económico). Um outro objetivo que este estudo demonstra é a importância do trabalho científico em parceria porque o grupo de investigadores engloba elementos de prestigiadas instituições médicas e de saúde situadas nos seguintes países: Índia, Estados Unidos da América, China e Canadá.

Investigar nas áreas da medicina e da saúde é, cada vez mais, uma atividade destinada não só a estimular as descobertas científicas mas também a promover a melhoria da qualidade de vida das pessoas em qualquer local do mundo onde se encontrem.

António Rendas

Nova Medical School, Faculdade de Ciências Médicas, Universidade Nova de Lisboa. 